\title{
Effectiveness of Special Strength Training on Some Physical and Kinetic Parameters Affecting Instep Kick for Soccer Juniors
}

\author{
Ehab Hamed El-Berawy*, Amr Aly Shady**
}

\begin{abstract}
Objectives: To examine special strength training program effects on physical variables and kinetic variables affecting instep kick for the soccer juniors.

Design: Special Strength training program was applied for 12 weeks, 3 trainings a week lasting from 60 - 80 minutes each.

Participants: 20 soccer juniors were equally and randomly divided into two groups experimental $(n=10)$ and control $(n=10)$ groups.

Main Outcome Measures: The anthropometric (height and weight) and physical tests (isometric back and leg strength test, Quadrant jump test, vertical jump, Illinois agility test), testing skill (accuracy kick on goal), and photography with movement analysis used high-speed video camera (250 frame/s via Simi motion analysis system).

Results: Statistically differences were found on physical tests (isometric back and leg strength, Quadrant jump, vertical jump, Illinois agility tests), testing skill (accuracy kick on goal) and kinetic variables between control and experimental groups.

Conclusions: Although there is statistically significance for the experimental group, the special strength training is a very specific way to train as the experimental evidence for this workout demonstrates. It involves mainly weight bearing activities and some core muscle group exercises that are believed to be very important for soccer juniors.
\end{abstract}

Key words: soccer, special strength, instep kick, kinetic

\section{Introduction}

$\mathrm{S}$ occer is thought to be one of the most demanding sports of all team sports. In the modern game (at any level) soccer training and conditioning is essential. During a soccer game, each player performs several dynamic movements (headers, cutting, tackling, sprints and kicks) which require a highly level of muscle strength, power and endurance (Cabri et al., 1988; Bangsbo, 1994). Strength in its different forms (maximum strength, explosive strength and rate of force development) plays a critical role on the performance of such

\footnotetext{
* Lecturer, Faculty of Physical Education, Mansoura University, Egypt.

** Lecturer, Faculty of Physical Education, Mansoura University, Egypt.
}

skills (Cabri et al., 1988). Soccer practice suggests that a soccer player needs to develop a level of maximum strength and power, which is utilized effectively within the game (Buhrle, 1985).

One of the most important skills in soccer is the instep kick, it constitutes a basic element of a soccer game when a faster

and more powerful ball needs to be generated (Inoue et.al. 2012). It is a multi-joint activity which depends on various factors, such as the maximum strength and power of muscles activated during the kick (De Proft et al., 1988 a, b; Weineck, 1992; Lees \& Nolan, 1998; Dorge et al., 1999), the timing and appropriate transfer of energy through the co-operation of the hip, knee and ankle joints all together in a chain reaction, transferring the base energy between 
segments that participate in the kick (Noguchi1, 2012), the speed and angle of approach of the player to the ball (Opavsky, 1988) and the utilization of the stretch-shortening cycle characteristics by the muscles of the kicking leg (Weineck, 1992).

The researchers noted that all force generated by the musculoskeletal system in the upper and lower body either originates, is stabilized by, or transferred through the trunk and low torso.

Given this fact, if athletes are to develop their full strength and power potentials, a significant portion of strength and conditioning program should focus on developing the core muscles low back. A good example of this is athletes who have a strong, powerful lower body, but do not reach full potential in vertical jumping due to weakness in the core part of the body (Include evidence to support this statement).

The most important characteristics of special strength training are; focusing on developing the core muscles and the multi-directional multiplicity of levels and joints that lead them, controlling of the reverse-balance, single limb movements, integrative, specific activity of the practitioner, the specific speed and its interest in the alternating parts in the motor performance of the performed skill (Schmitz, 2003).

However, there have been very limited studies that examined the effects of soccer training programs on soccer kick. The examination of how these characteristics are altered through training can be practically more useful. The importance of this study, as one of the experimental studies, may provide information that can benefit trainers in the field of the training junior as they enter into research treatment that addresses the problems of training, particularly on the side of the skill mastering.

\section{Aim of Research}

This research aims to identify the effectiveness of special strength training on:

- Physical parameters affecting instep kick for soccer juniors in control and experimental groups.
- Kinetic parameters affecting instep kick for soccer juniors in control and experimental groups.

- The difference in physical variables and kinetic variables between control and experimental groups.

\section{Hypotheses}

- There are significant differences between the pre-test and post-test measurement of experimental group in the physical variables affecting the instep kick of soccer junior for the post-test.

- There are significant differences between the pre-test and post test measurement of experimental group in the kinetic variable affecting the instep kick of soccer junior for the post test.

- There are significant differences between the control and experimental groups in the post test measurement of

- physical variable affecting in instep

- kick for soccer junior.

- There are significant differences between the control and experimental groups in the post test measurement of

- kinetic variable affecting in instep kick for soccer junior.

\section{Methods}

\section{Study design}

A 12-week prospective intervention was used to assess the effects of Special Strength training program on some physical variable(Isometric back and leg strength test, Quadrant jump test , vertical jump, Illinois agility test), Testing skill (Accuracy kick on goal) and kinetic variable affecting instep kick for soccer junior. Participants were randomly assigned to either an experimental group or control group .The experimental group performed the Special Strength training program three time per week for 12 weeks, whereas the control group received traditional training. Prior to and following the 12-week intervention(Isometric 
back and leg strength test, Quadrant jump test , vertical jump, Illinois agility test), Testing skill (Accuracy kick on goal) and kinetic variable affecting in instep kick.

\section{Participants}

Twenty soccer junior volunteered to participate in this investigation. All of the participants had a minimum of 5 years of soccer federation and were involved in intramural soccer at the time of the study. Descriptive characteristics for each group are listed in Table 1.

\section{Strength training special}

Details of the Sports metrics training program have been previously reported the strength portion form.

He following paragraph represents research methods and not research hypotheses.

Sports metrics were performed 3 days per week for 12 weeks. Each session lasted approximately 60-80 min and included a standardized warm-up, followed by Strength exercises special and concluded with a cool-down. A variety of Special Strength exercises were performed during the 12 weeks intervention and are outlined in Table 2 . All participants completed an orientation session to become familiar with the Strength drills prior to the initial training session, but following pre-testing. All training sessions were supervised by the same investigator throughout the study.

\section{Experimental Method}

- Experimental method using (pre-test and posttest), were used for twenty Junior soccer players (aged $18.69 \pm 0.7$ years, body mass: $71.18 \pm 2.9 \mathrm{~kg}$, height: $176.17 \pm 3.2 \mathrm{~cm}$ ) constituted two equal groups, the experimental group and control group.

- The researcher utilised video motion analyses using a high-speed video camera, Sports Cam at frequency $250 \mathrm{frame} / \mathrm{s}$ and movement analysis via Motion Analysis Program (Simi motion add date for program).

\section{Procedures}

- Pre-test measurements included anthropometric measurements of height $(\mathrm{cm})$ and weight $(\mathrm{kg})$; physical testing including tests of Standing Balance Test to test static balance, using: flat, non-slip surface and stopwatch (s); isometric back and leg Strength test to measures back and leg strength, using: strength dynamometer and composed of a cable tensiometer; Illinois Agility Test to test running agility, using: flat non-slip surface, marking cones, stopwatch, measuring tape and timing gates; Quadrant Jump Test to measures speed change of direction using tape measure, chalk or tape for marking the ground, and stopwatch; and Vertical Jump Test to measures power using: measuring tape or marked wall and chalk for marking wall.

- Testing Skill - Accuracy kick on goal using video photography and analysis of motor skill for instep kick, kicked the static ball with maximal effort towards a target $16.5 \mathrm{~m}$ away, perpendicular to the points penalty, this goal is divided into 9 boxes. Kick timing and maximal performance velocity was recorded using a speed video camera.

- Special strength training program has been applied for (12) weeks, (3) trainings a week lasting for 80 minutes of training each, on Saturday.

- The stabilization of deep muscles that stabilize the spine and superficial muscles that move the spine are thought to be represented by: Transverse abdominis (TVA), Multifidus muscle, External obliques, Internal obliques, Rectus abdominis, Erector spine; and leg muscles of quadriceps, Gracilis, gastrocnemius, Plantaris, Sartorius, Adductor magnus, Semitendinosus, Semimembranosus and Biceps femoris.

- The post-tests were conducted in the same order of the pre-tests.

\section{Statistical Analysis}

The statistical analyses of means, standard deviations, median, coefficient of skewness and T-tests were applied. 
Table (1)

Descriptive characteristics and differences between experimental and control groups for physical variables.

\begin{tabular}{|l|c|c|l|}
\hline & $\begin{array}{l}\text { Experimental }(\mathrm{n}=10) \\
\text { Pre-test }\end{array}$ & $\begin{array}{l}\text { Control }(\mathrm{n}=10) \\
\text { Pre-test }\end{array}$ & $\begin{array}{l}p \text { - } \\
\text { Nalue }\end{array}$ \\
\hline Age (year) & $18.42 \pm 2.34$ & $18.95 \pm 3.2$ & 0.89 \\
Height (cm) & $176.35 \pm 3.26$ & $175.67 \pm 4.32$ & 0.64 \\
Body mass (kg) & $70.41 \pm 2.61$ & $71.69 \pm 3.54$ & 0.23 \\
Isometric back strength (kg) & $69.27 \pm 1.87$ & $68.59 \pm 2.04$ & 0.61 \\
Isometric leg strength (kg) & $05.24 \pm 4.28$ & $107.39 \pm 3.94$ & 0.48 \\
Quadrant jump (s) & $3.92 \pm 0.043$ & $3.89 \pm 0.031$ & 0.57 \\
Illinois agility (s) & $13.41 \pm 0.61$ & $13.57 \pm 0.87$ & 0.39 \\
Vertical jump (cm) & $48.23 \pm 0.98$ & $50.01 \pm 1.03$ & 0.28 \\
Accuracy kick (degree) & $2.74 \pm 0.091$ & $2.81 \pm 0.042$ & 0.54 \\
Kick time (s) & $0.36 \pm 0.021$ & $0.35 \pm 0.032$ & 0.42 \\
\hline
\end{tabular}

Values are mean +/-SD, p-Value was computed using independent samples T-Test.

Table 1. Indicates there are no significant differences between experimental and control groups at the pre-test stage in the physical variables.

\section{Results} The results indicate the existence of significant test. differences between pre-test and post-test scores for the experimental group in the physical variables, such as strength of back muscles speed change of body direction - fast force power, agility, accuracy kick and kick timing. Table 2 includes the treatment benefits at post-

Table (2)

Differences between pre-test and post-test for physical variables in experimental group

\begin{tabular}{|c|c|c|c|}
\hline & \multirow{2}{*}{$\begin{array}{l}\text { Experimental }(n=10) \\
\text { Pre-test }\end{array}$} & \multirow[b]{2}{*}{ Post-test } & \multirow[t]{2}{*}{$p$-Value } \\
\hline & & & \\
\hline Isometric back strength $(\mathrm{kg})$ & $69.27 \pm 1.87$ & $75.29 \pm 3.54$ & 0.017 \\
\hline Isometric leg strength $(\mathrm{kg})$ & $105.24 \pm 4.28$ & $131.49 \pm 4.61$ & 0.013 \\
\hline Quadrant jump (s) & $3.92 \pm 0.043$ & $3.32 \pm 0.041$ & 0.01 \\
\hline Illinois agility (s) & $13.41 \pm 0.61$ & $11.84 \pm 0.68$ & 0.012 \\
\hline Vertical jump $(\mathrm{cm})$ & $48.23 \pm 0.98$ & $74.19 \pm 2.03$ & 0.003 \\
\hline Accuracy kick (degree) & $2.74+0.091$ & $4.35 \pm 0.051$ & 0.004 \\
\hline Kick time (s) & $0.36+0.021$ & $0.29+0.015$ & 0.014 \\
\hline
\end{tabular}

Values are mean, +/-SD, p-Value was computed using paired-samples T-Test

Table 2 indicates that there is a significant difference between (pre-test, post-test) of physical variables in experimental group for the benefit of post-test.

This results indicate shown significant differences between experimental and control groups, physical variables (strength of the legs and back muscles - speed change of body direction, fast force power), agility, accuracy kick and kick timing, the benefits favouring the post-test, experimental group as shown in table 3. 
Table (3)

Differences between experimental and control groups for physical variables.

\begin{tabular}{|l|c|c|c|l|l|}
\hline & Experimental $(\mathrm{n}=10)$ & & Control $(\mathrm{n}=10)$ & & $p$-Value \\
\cline { 2 - 2 } & Pre-test & & Post-test & \\
\hline Isometric back strength $(\mathrm{kg})$ & $75.29 \pm 3.54$ & & $71.59 \pm 2.34$ & \\
Isometric leg strength $(\mathrm{kg})$ & $131.49 \pm 4.61$ & & $115.27 \pm 5.06$ & \\
Quadrant jump (s) & $3.32 \pm 0.041$ & & $3.75 \pm 0.98$ & \\
Illinois agility (s) & $11.84 \pm 0.68$ & & 0.002 \\
Vertical jump (cm) & $74.19 \pm 2.03$ & & $13.02 \pm 1.39$ & \\
Accuracy kick (degree) & $4.35 \pm 0.051$ & & $56.28 \pm 2.41$ & & 0.001 \\
Kick time (s) & $0.29 \pm 0.015$ & & $3.01 \pm 0.94$ & \\
\hline
\end{tabular}

Values are mean +/-SD, p-Value was computed using Independent samples T-Test.

This study displayed the existence of significant differences between pre-test and post-test scores of the experimental group in the kinetic variable. Such as angular displacement $(\theta)$, linear displacement (SR), angular velocity $(\omega)$, linear velocity (VR), linear acceleration $(\mathrm{aR})$ ) in stages of skill (backswing, impact, and followup) variables in three point the hip, knee and ankle joint). The trends for post-test scores are shown in Table 4.

Figure (1)

Average of kinetic linear velocity in past-test for experimental group.

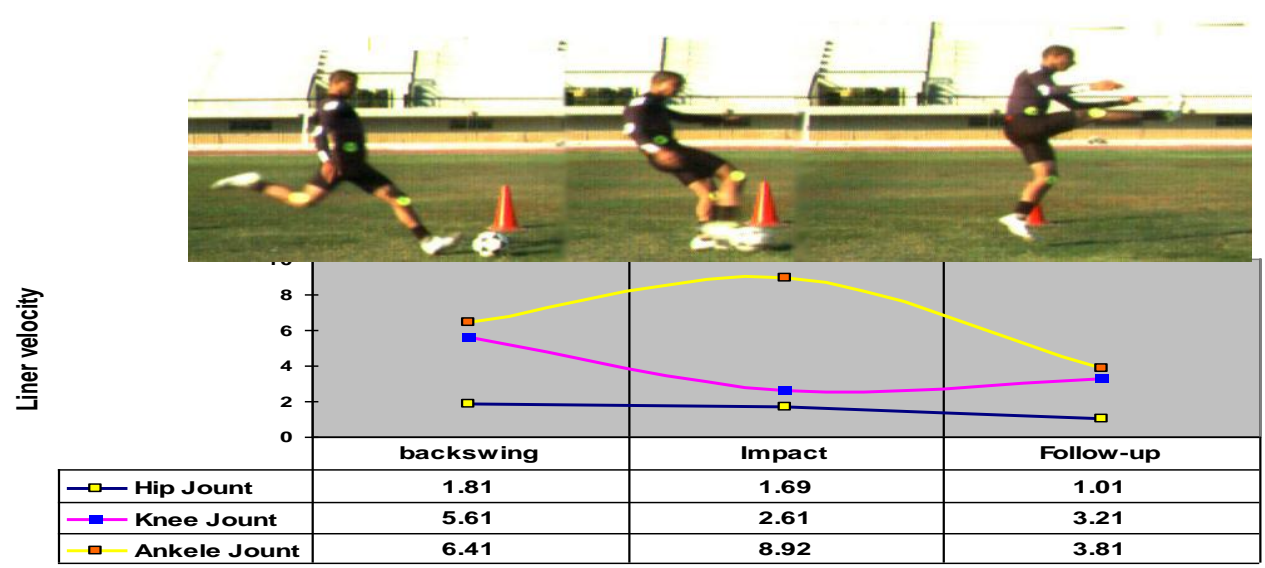

Figure (2)

Average kinetic linear acceleration in post-test for experimental group.

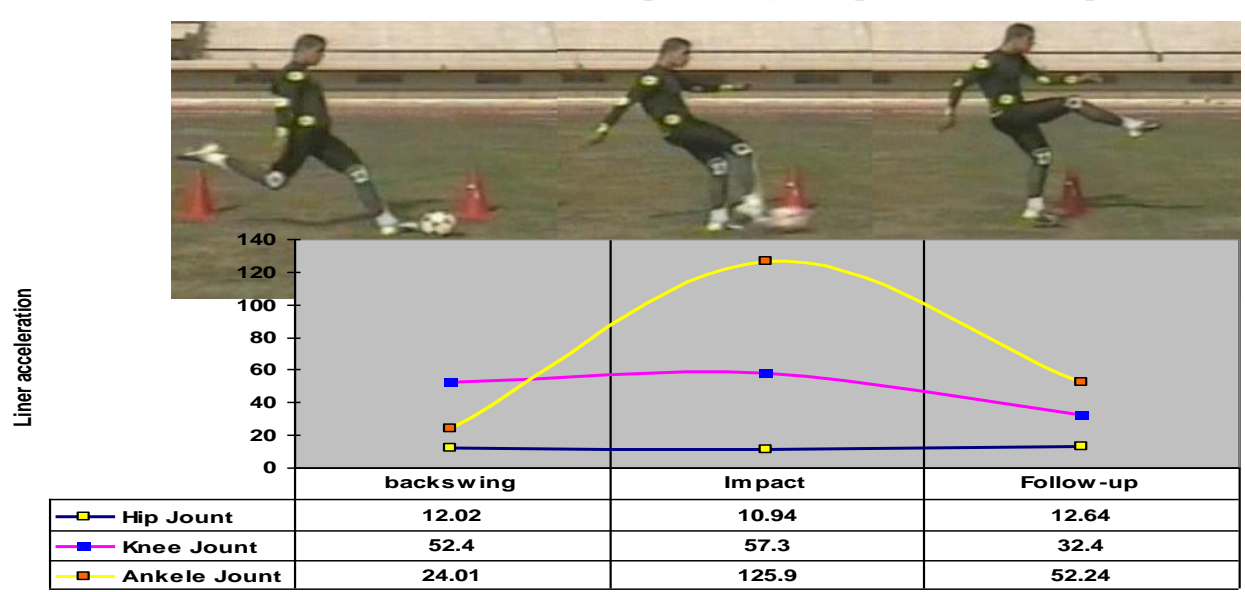


Table (4)

Differences between pre-test, post-test scores of kinetic variables in experimental group.

\begin{tabular}{|c|c|c|c|c|}
\hline \multirow{2}{*}{ Hip Joint } & \multirow{2}{*}{$\begin{array}{l}\text { Stages of } \\
\text { skill }\end{array}$} & $\begin{array}{l}\text { Experimental } \\
(n=10)\end{array}$ & & $p$-Value \\
\hline & & Pre-test & Post-test & \\
\hline \multirow{3}{*}{ Angular displacement $(\theta)$} & \multirow{3}{*}{$\begin{array}{l}\text { backswing } \\
\text { Impact } \\
\text { Follow-up }\end{array}$} & $164.4 \pm 2.39$ & $174.23 \pm 2.94$ & 0.012 \\
\hline & & $124.7 \pm 1.92$ & $130.8 \pm 1.65$ & 0.003 \\
\hline & & $116.3 \pm 1.24$ & $118.7 \pm 1.08$ & 0.002 \\
\hline \multirow{3}{*}{ Linear displacement $\left(\mathrm{S}^{\mathrm{R}}\right)$} & \multirow{3}{*}{$\begin{array}{l}\text { backswing } \\
\text { Impact } \\
\text { Follow-up }\end{array}$} & $0.279 \pm 0.01$ & $0.351 \pm 0.02$ & 0.002 \\
\hline & & $0.202 \pm 0.004$ & $0.27 \pm 0.01$ & 0.001 \\
\hline & & $0.284 \pm 0.011$ & $0.36 \pm 0.03$ & 0.004 \\
\hline \multirow{3}{*}{ Angular velocity $(\omega)$} & \multirow{3}{*}{$\begin{array}{l}\text { backswing } \\
\text { Impact } \\
\text { Follow-up }\end{array}$} & $-11.86 \pm 0.534$ & $-18.94 \pm 1.25$ & 0.003 \\
\hline & & $-0.401 \pm 0.04$ & $-0.61 \pm 0.02$ & 0.011 \\
\hline & & $7.17 \pm 0.864$ & $9.21 \pm 0.75$ & 0.011 \\
\hline \multirow{3}{*}{ Linear velocity $\left(\mathrm{V}^{\mathrm{R}}\right)$} & \multirow{3}{*}{$\begin{array}{l}\text { backswing } \\
\text { Impact } \\
\text { Follow-up }\end{array}$} & $1.28 \pm 0.07$ & $1.81 \pm 0.43$ & 0.002 \\
\hline & & $1.49 \pm 0.31$ & $1.69 \pm 0.27$ & 0.003 \\
\hline & & $0.72 \pm 0.09$ & $1.01 \pm 0.32$ & 0.014 \\
\hline \multirow{3}{*}{ Liner acceleration $\left(\mathrm{a}^{\mathrm{R}}\right)$} & \multirow{3}{*}{$\begin{array}{l}\text { backswing } \\
\text { Impact } \\
\text { Follow-up }\end{array}$} & $12.02 \pm 0.86$ & $13.98 \pm 0.59$ & 0.002 \\
\hline & & $10.94 \pm 0.61$ & $13.6 \pm 0.71$ & 0.001 \\
\hline & & $12.64 \pm 0.76$ & $15.7 \pm 0.86$ & 0.00 \\
\hline \multicolumn{5}{|l|}{ Knee Joint } \\
\hline \multirow{3}{*}{ Angular displacement $(\theta)$} & \multirow{3}{*}{$\begin{array}{l}\text { backswing } \\
\text { Impact } \\
\text { Follow-up }\end{array}$} & $65.31 \pm 1.24$ & $68.1 \pm 0.94$ & 0.002 \\
\hline & & $110.1 \pm 1.28$ & $112.94 \pm 1.38$ & 0.0011 \\
\hline & & $171.4 \pm 2.31$ & $178.2 \pm 3.21$ & 0.003 \\
\hline \multirow{3}{*}{ Linear displacement $\left(\mathrm{S}^{\mathrm{R}}\right)$} & \multirow{3}{*}{$\begin{array}{l}\text { backswing } \\
\text { Impact } \\
\text { Follow-up }\end{array}$} & $0.249 \pm 0.01$ & $0.31 \pm 0.03$ & 0.002 \\
\hline & & $1.98 \pm 0.23$ & $2.01 \pm 0.37$ & 0.003 \\
\hline & & $2.62 \pm 0.34$ & $2.71 \pm 0.12$ & 0.012 \\
\hline \multirow{3}{*}{ Angular velocity $(\omega)$} & \multirow{3}{*}{$\begin{array}{l}\text { backswing } \\
\text { Impact } \\
\text { Follow-up }\end{array}$} & $-1.84 \pm 0.37$ & $-2.45 \pm 0.12$ & 0.002 \\
\hline & & $14.1 \pm 1.62$ & $18.94 \pm 1.34$ & 0.013 \\
\hline & & $0.281 \pm 0.04$ & $0.34 \pm 0.012$ & 0.003 \\
\hline \multirow{3}{*}{ Linear velocity $\left(\mathrm{V}^{\mathrm{R}}\right)$} & \multirow{3}{*}{$\begin{array}{l}\text { backswing } \\
\text { Impact } \\
\text { Follow-up }\end{array}$} & $4.53 \pm 0.95$ & $5.61 \pm 0.37$ & 0.000 \\
\hline & & $1.27 \pm 0.21$ & $2.61 \pm 0.13$ & 0.001 \\
\hline & & $2.7 \pm 0.84$ & $3.21 \pm 0.81$ & 0.003 \\
\hline \multirow{3}{*}{ Linear acceleration $\left(\mathrm{a}^{\mathrm{R}}\right)$} & & $52.4 \pm 3.41$ & $55.32 \pm 2.84$ & 0.002 \\
\hline & Impact & $57.3 \pm 1.31$ & $60.01 \pm 2.03$ & 0.001 \\
\hline & & $32.4 \pm 0.95$ & $35.02 \pm 0.59$ & 0.002 \\
\hline Ankle Joint & & & & \\
\hline & backswing & $152.3 \pm 4.35$ & $152.9 \pm 4.61$ & 0.015 \\
\hline Angular displacement $(\theta)$ & Impact & $127.9 \pm 5.31$ & $132.5 \pm 3.91$ & 0.12 \\
\hline & Follow-up & $139.7 \pm 5.49$ & $140.1 \pm 5.42$ & 0.031 \\
\hline & backswing & $0.381 \pm 0.01$ & $0.42 \pm 0.01$ & 0.012 \\
\hline Linear displacement $\left(S^{R}\right)$ & Impact & $0.420 \pm 0.011$ & $0.45 \pm 0.011$ & 0.017 \\
\hline & Follow-up & $0.612 \pm 0.02$ & $0.68 \pm 0.02$ & 0.013 \\
\hline & backswing & $3.54 \pm 0.51$ & $4.59 \pm 0.98$ & 0.021 \\
\hline Angular velocity $(\omega)$ & Impact & $3.01 \pm 0.21$ & $4.67 \pm 0.94$ & 0.011 \\
\hline & Follow-up & $1.52 \pm 0.04$ & $1.94 \pm 0.046$ & 0.003 \\
\hline & backswing & $5.21 \pm 1.36$ & $6.41 \pm 1.05$ & 0.014 \\
\hline Linear velocity $\left(\mathrm{V}^{\mathrm{R}}\right)$ & Impact & $5.84 \pm 0.98$ & $8.92 \pm 1.71$ & 0.11 \\
\hline & Follow-up & $2.61 \pm 0.18$ & $3.81 \pm 0.93$ & 0.021 \\
\hline & backswing & $24.01 \pm 0.91$ & $28.35 \pm 2.04$ & 0.001 \\
\hline Linear acceleration $\left(\mathrm{a}^{\mathrm{R}}\right)$ & Impact & $125.9 \pm 2.67$ & $131.9 \pm 5.06$ & 0.002 \\
\hline & Follow-up & $52.24 \pm 3.58$ & $55.01 \pm 2.95$ & 0.015 \\
\hline
\end{tabular}

Values are mean +SD .p-Value was computed using paired-samples T Test.

Table 4 indicates significant differences between pre-test and post-test of the experimental group in the measurements of angular displacement, linear displacement, angular velocity, linear velocity and linear acceleration for the pre-test to post-test in hip joint, knee joint and ankle joint. 
Table (5)

Differences between training and control of kinetic variables in experimental group.

\begin{tabular}{|c|c|c|c|c|}
\hline \multirow[t]{2}{*}{ Hip Joint } & \multirow{2}{*}{$\begin{array}{c}\text { Stages of } \\
\text { skill }\end{array}$} & $\begin{array}{l}\text { Experimental } \\
\qquad(\mathrm{n}=10)\end{array}$ & $\begin{array}{l}\text { Control } \\
(n=10)\end{array}$ & $p$-Value \\
\hline & & Post-test & Post-test & \\
\hline \multirow{3}{*}{$\begin{array}{l}\text { Angular displacement } \\
\qquad(\theta)\end{array}$} & \multirow{3}{*}{$\begin{array}{l}\text { backswing } \\
\text { Impact } \\
\text { Follow-up }\end{array}$} & $174.23 \pm 2.94$ & $165.31 \pm 3.21$ & 0.002 \\
\hline & & $130.8 \pm 1.65$ & $126.1 \pm 2.01$ & 0.014 \\
\hline & & $118.7 \pm 1.08$ & $116.9 \pm 2.35$ & 0.001 \\
\hline \multirow{3}{*}{ Liner displacement $\left(S^{R}\right)$} & \multirow{3}{*}{$\begin{array}{l}\text { backswing } \\
\text { Impact } \\
\text { Follow-up }\end{array}$} & $0.351 \pm 0.02$ & $0.281 \pm 0.03$ & 0.003 \\
\hline & & $0.27 \pm 0.01$ & $0.24 \pm 0.013$ & 0.002 \\
\hline & & $0.36 \pm 0.03$ & $0.287 \pm 0.04$ & 0.001 \\
\hline \multirow{3}{*}{ Angular velocity $(\omega)$} & \multirow{3}{*}{$\begin{array}{l}\text { backswing } \\
\text { Impact } \\
\text { Follow-up }\end{array}$} & $-18.94 \pm 1.25$ & $-12.01 \pm 1.37$ & 0.000 \\
\hline & & $-0.61 \pm 0.02$ & $-0.52 \pm 0.03$ & 0.021 \\
\hline & & $9.21 \pm 0.75$ & $8.14 \pm 0.101$ & 0.003 \\
\hline \multirow{3}{*}{ Liner velocity $\left(\mathrm{V}^{\mathrm{R}}\right)$} & \multirow{3}{*}{$\begin{array}{l}\text { backswing } \\
\text { Impact } \\
\text { Follow-up }\end{array}$} & $1.81 \pm 0.43$ & $1.32 \pm 0.061$ & 0.001 \\
\hline & & $1.69 \pm 0.27$ & $1.46 \pm 0.018$ & 0.005 \\
\hline & & $1.01 \pm 0.32$ & $0.74 \pm 0.21$ & 0.003 \\
\hline \multirow{3}{*}{ Liner acceleration $\left(\mathrm{a}^{\mathrm{R}}\right)$} & \multirow{3}{*}{$\begin{array}{l}\text { backswing } \\
\text { Impact } \\
\text { Follow-up }\end{array}$} & $13.98 \pm 0.59$ & $11.95 \pm 1.06$ & 0.001 \\
\hline & & $13.6 \pm 0.71$ & $10.68 \pm 1.51$ & 0.001 \\
\hline & & $15.7 \pm 0.86$ & $12.34 \pm 1.74$ & 0.001 \\
\hline \multicolumn{5}{|l|}{ Knee Joint } \\
\hline \multirow{3}{*}{$\begin{array}{l}\text { Angular displacement } \\
\qquad(\theta)\end{array}$} & \multirow{3}{*}{$\begin{array}{l}\text { backswing } \\
\text { Impact } \\
\text { Follow-up }\end{array}$} & $68.1 \pm 0.94$ & $64.32 \pm 2.36$ & 0.004 \\
\hline & & $112.94 \pm 1.38$ & $109.7 \pm 5.67$ & 0.001 \\
\hline & & $178.2 \pm 3.21$ & $168.24 \pm 5.42$ & 0.002 \\
\hline \multirow{3}{*}{ Liner displacement $\left(\mathrm{S}^{\mathrm{R}}\right)$} & \multirow{3}{*}{$\begin{array}{l}\text { backswing } \\
\text { Impact } \\
\text { Follow-up }\end{array}$} & $0.31 \pm 0.03$ & $0.26 \pm 0.012$ & 0.002 \\
\hline & & $2.01 \pm 0.37$ & $1.84 \pm 0.021$ & 0.001 \\
\hline & & $2.71 \pm 0.12$ & $2.37 \pm 0.92$ & 0.012 \\
\hline \multirow{3}{*}{ Angular velocity $(\omega)$} & \multirow{3}{*}{$\begin{array}{l}\text { backswing } \\
\text { Impact } \\
\text { Follow-up }\end{array}$} & $-2.45 \pm 0.12$ & $-1.68 \pm 0.38$ & 0.002 \\
\hline & & $18.94 \pm 1.34$ & $13.89 \pm 1.09$ & 0.013 \\
\hline & & $0.34 \pm 0.012$ & $0.27 \pm 0.03$ & 0.003 \\
\hline \multirow{3}{*}{ Liner velocity $\left(\mathrm{V}^{\mathrm{R}}\right)$} & \multirow{3}{*}{$\begin{array}{l}\text { backswing } \\
\text { Impact } \\
\text { Follow-up }\end{array}$} & $5.61 \pm 0.37$ & $4.35 \pm 0.68$ & 0.000 \\
\hline & & $2.61 \pm 0.13$ & $1.34 \pm 0.05$ & 0.001 \\
\hline & & $3.21 \pm 0.81$ & $2.65 \pm 0.018$ & 0.002 \\
\hline \multirow{3}{*}{ Liner acceleration $\left(a^{R}\right)$} & & $55.32 \pm 2.84$ & $51.8 \pm 0.193$ & 0.002 \\
\hline & Impact & $60.01 \pm 2.03$ & $56.97 \pm 1.72$ & 0.001 \\
\hline & & $35.02 \pm 0.59$ & $33.45 \pm 1.34$ & 0.002 \\
\hline Ankle Joint & & & & \\
\hline & backswing & $152.9 \pm 4.61$ & $151.7 \pm 5.31$ & 0.015 \\
\hline Angular displacement & Impact & $132.5 \pm 3.91$ & $126.9 \pm 4.58$ & 0.021 \\
\hline & Follow-up & $140.1 \pm 5.42$ & $138.4 \pm 3.94$ & 0.031 \\
\hline & backswing & $0.42 \pm 0.01$ & $0.362 \pm 0.029$ & 0.012 \\
\hline Liner displacement $\left(\mathrm{S}^{\mathrm{R}}\right)$ & Impact & $0.45 \pm 0.011$ & $0.394 \pm 0.031$ & 0.012 \\
\hline & Follow-up & $0.68 \pm 0.02$ & $0.597 \pm 0.06$ & 0.011 \\
\hline & backswing & $4.59 \pm 0.98$ & $3.27 \pm 0.94$ & 0.001 \\
\hline Angular velocity $(\omega)$ & Impact & $4.67 \pm 0.94$ & $2.96 \pm 0.99$ & 0.011 \\
\hline & Follow-up & $1.94 \pm 0.046$ & $1.48 \pm 0.81$ & 0.003 \\
\hline & backswing & $6.41 \pm 1.05$ & $5.31 \pm 1.39$ & 0.002 \\
\hline Liner velocity $\left(\mathrm{V}^{\mathrm{R}}\right)$ & Impact & $8.92 \pm 1.71$ & $5.74 \pm 1.46$ & 0.016 \\
\hline & Follow-up & $3.81 \pm 0.93$ & $2.51 \pm 0.81$ & 0.011 \\
\hline & backswing & $28.35 \pm 2.04$ & $23.68 \pm 2.36$ & 0.001 \\
\hline Liner acceleration $\left(\mathrm{a}^{\mathrm{R}}\right)$ & Impact & $131.9 \pm 5.06$ & $124.93 \pm 6.15$ & 0.004 \\
\hline & Follow-up & $55.01 \pm 2.95$ & $49.87 \pm 2.48$ & 0.001 \\
\hline
\end{tabular}

Values are mean $+S D$.p-Value was computed using Independent samples T Test.

Table 5 Significant differences between the experimental group and control group in the measurements of angular displacement, liner displacement, angular velocity, linear velocity and linear acceleration in favour of the training group in hip, knee and ankle joints.

\section{Discussion}

\section{Physical Parameters}

This study indicates significant differences between the experimental and control groups in the measurements of strength of the legs and 
back muscles, speed change of body direction, fast force power, agility, accuracy kick and kick timing and indicate significant improvement in these variables for the experimental group. This is logical in terms of performance of the skill of good soccer players. Since the accuracy kick, which reached its highest value is the outcome of the economy in the effort represented in the fast force power and balance the skill during the performance. The special strength training has helped in the development of strength of the leg muscles. The researchers believe the instep kick in soccer require multiple amounts of power to complete the motor task of kicking and must regulate the force exerted and distribution and direct them to lead to the production of kinetic energy, as well as in turn lead to successful motor performance, which was contributed to by the special strength training. Those results agree with (Chek, 2001, Cunningham, 2000, Comana, 2004, Jones, 2003, Gaines, 2003), that the special strength training is a very specific way to train as this simple workout used in this study demonstrates. It involves mainly weight bearing activities and some core muscle group exercises that appear to be very important for soccer players. We can finally say that special strength training is valuable and even crucial for success of modern soccer players.

\section{Kinetic Parameters}

This study demonstrates significant differences between the experimental and control groups in the kinetic variables for the hip joint during instep kick of the experimental group in maximum back swing. There were significant differences in angular velocity, linear velocity, angular momentum and in favour of experimental group. As well as significant differences in moment of inertia as shown in table 5. The researchers attributed the increased percentages of improvement in the angular displacement and angular velocity.

At the moment the player performs the maximum back swing the angular displacement and linear displacement cause the increase of the primary stage motor scale. Through the forward shifting the linear velocity, angular velocity and acceleration increase. While at the moment of impact the maximum velocity is in the metatarsal then knee then hip as the metatarsal is the end of motor chain.
As a result of increasing the scale of the back swing, the motor scale and performance time increase which, leads to increasing of movement quantum through the primary stage. This increasing of the movement quantum gives greater preference to the impulse of instep kick till the end of the stage, where impulse $=$ force $\mathrm{x}$ time. These results agree with Jin Wang and Mike Griffin (1997) recommendations.

During this phase, the hyper extension occurs in the hip, this will result in joint muscles generating a high degree of tension and it contributes to storing of large amounts of mechanical energy in the muscle and with the beginning of back to the movement the energy is recovered and transferred to the ball at the moment of impact. We believe that this outcome is due to the special strength training which in increased speed of movement of muscles of the hip joint (Hossam El-Din, 1993; Manolopoulos, 2004). The thigh muscles that allow a large dynamic range increases the effectiveness of the movement of the distal end and give it the necessary force during movement, as is the case of kicking the ball.

For the knee joint during the instep kick of the experimental group impact moment, shown in table 5, there was a significant differences between experimental and control groups in angular displacement, linear displacement, angular velocity, linear velocity and angular momentum in favour of the experimental group. The researchers attributed the increased improvement to linear displacement, angular displacement, angular velocity, linear velocity and angular momentum of the knee joint in the moment of impact.

As a result of decreasing the hip joint speed at the moment of impact with the ball, the angular displacement, angular velocity and linear acceleration of the knee joint increase.

This agree with Barfield (1998) using EMG measurements, who found maximal activity of hip and knee muscles during the terminal stage of the backswing phase which increased again, prior to ball impact. The activity levels were higher for all muscles throughout the kick, whereas proximal-to-distal sequence of muscle activation was not evident. From the above description, it becomes clear that the rapid knee flexion and extension is an important aspect of 
soccer kick performance (De Proft et al., 1988). This movement is accompanied by a stretch of the knee extensor musculature during backswing followed by immediate shortening during forward shank movement. It has been shown that kicking speed is significantly higher when the knee extensor musculature is stretched and then shorten compared with kicks involving only concentric actions.

It is clear from Table 4 that significant differences occur between the experimental and control groups in kinetic variables. For ankle joint during instep kick impact moment there were significant difference between the experimental and control groups in angular displacement, angular velocity, linear velocity, angular momentum in favour of the experimental group. The researchers attributed the increased improvement to angular displacement, angular velocity, linear velocity, angular momentum, of the ankle joint in the moment of impact. The Soccer kick is characterized by segmental and joint rotations in multiple planes and that the instep kick is one of the movements that belong to the open kinetic chains, which aimed to produce high angular velocity of the feet through profile kinematic for segments to various anatomical structures involved in the performance. This explanation agrees with (Masuda, et. al., 2005; Manolopoulos., et. al., 2006). At ball impact the thigh angular velocity is almost $\mathrm{z}$ ero while the shank and the foot reach peak angular velocity.

\section{Conclusion}

The results of this study indicate the existence of significant improvements in the physical variables, skill performance level, time and kinematic variables of the instep kick for the experimental group.

Based on these improvements the researchers recommended that the special strength training should be an essential part of the training program for soccer players. The researchers also recommended that the soccer coaches should develop the special strength training and the kinematic variables to enhance their players performance.

\section{References}

1. Bangsbo J. Physical Conditioning Training in Soccer: A Scientific Approach. In: Copenhagen, Denmark University of Copenhagen, 1994.

2. Barfield B. The Kinetic of Kicking in Soccer. In: Clinicsin Sports Medicine,17(4): 711728,1998 .

3. Cabri, J., De Proft, E., Dufour, W. \& Clarys, J. The Relation between Muscular Strength and Kick Performance. In: Science and Football. Eds: Reilly, T., Lees, A., Davids, K. and Murphy, W. London: E \& FN Spon. 186-193, 1988.

4. Chek, P. Big Bang Exercise. In: IDEA Fitness Edge, pp 8-10,2001.

5. Comana F. Function Training For Sports, In: Human Kinetics. Champaign IL, England,2004.

6. Cunningham $\mathrm{C}$. The Importance of Quality Strength Training. In: Personal Fitness Professional Magazine, American Council on Exercise publication, April, 2000.

7. De Proft E, Cabri J, Dufour W, Clarys J. Strength Training and Kick Performance in Soccer Players. Reilly T, Lees A, Davids K, Murphy WJ, eds. Science and football. London: E \& FN Spon, 109-113,1988.

8. Dorge H., et.al. EMG Activity Of The Iliopsoas Muscle And Leg Kinetics During The Soccer Place Kick. Scandinavian Journal of Medicine and Science in Sports, vol. 9, Issue 4, 195-200,1999.

9. Gaines S. Benefits and Limitations of Quality Exercise, Vertex Fitness .In: NESTA , USA,2003.

10. Hossam El-Din $\mathrm{T}$.Kinetic Of The Theoretical Foundations And Practical. In: House of the Arab Thought, Cairo, Egypt, 1993.

11. Inoue $\mathrm{K}$, et.al. Kinetic Analysis of The Support Leg In Soccer Instep Kicking. In: 30th Annual Conference of Biomechanics in Sports, Melbourne, 2012.

12. Jones R. Quality Training \#1: Introduction. In: Reebo Santana, Jose Carlos Uni. USA,2003.

13. Jin Wang, Mike Griffin. Kinematic Analysis of the Soccer Curve Ball Shot. In: National Strength \& Conditioning Association, vol. 19, no 1,54-55 February,1997. 
14. Lees A. \& Nolan L. The Kinetic of Soccer; A Review. In: Journal of Sport Science, 16: 211-234,1998.

15. Manolopoulos E., C. Papadopoulos C. \& Kellis E. Effects of Combined Strength And Kick Coordination Training On Soccer Kick Kinetic In Amateur Players. In : Scandinavian Journal of Medicine \& Science in Sports, vol. 16, Issue 2, 102-110,2006.

16. Manolopoulos, E., Papadopoulos, C., Salonikidis, K., Katartzi, E., Poluha, S. Strength training effects on physical conditioning and instep kick kinematics in young amateur soccer players during preseason. In: *Percept Motor Skills. 99: 701-710,2004.

17. Masuda K., Kikuhara N., Demura S., Katsuta S. \& Yamanaka K. Relationship Between Muscle Strength In Various Isokinetic Movements And Kick Performance Among Soccer Players. In: J. sports med. Phys. Fitness, $45,44-52,2005$.
18. Noguchi1 T., Demura S. \& Nagasawa Y. Relationship between Ball Kick Velocity and Leg Strength: A Comparison between Soccer Players and Other Athletes. In SciRes Vol.2, No.3,95-98, August 2012.

19. Opavsky P. An Investigation Of Linear And Angular Kinematics Of The Leg During Two Types Of Soccer Kick. In: Science and Football. Eds: Reilly, T., Lees, A., Davids, K. and Murphy, W.J. London: E \& FN Spon. 456459,1988.

20. Schmitz D. Quality Training Pyramids. In: New Truer High School, Kinetic Wellness Department, USA, 2003.

21. Weineck J. Optimales Fußballtraining. Teil 1: Kondition Straining des Fußballspielers. PERIMED-spitta, Medizin. Verlagsges., Nürnberg, 1992.

22. The complete Fitness Test list. In: http://www.topendsports.com/testing/ tests.

23. http://www.helium.com/items/1318922quality -resistance-training-for-soccer-athletes 